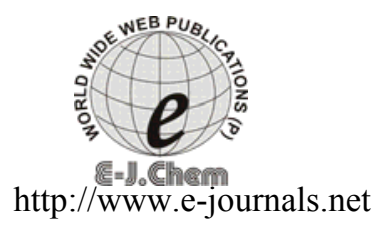

ISSN: 0973-4945; CODEN ECJHAO

E-Journal of Chemistry

2011, 8(S1), S481-S487

\title{
Investigation of Complexation of Linear Poly( $N$-vinyl-2-pyrrolidone) with Poly(methacrylic acid-co-methyl methacrylate) Gel
}

\author{
GUOQIN LIU*, GUOJIN YAN, WENJUN ZOU and ZHENGXIN LI \\ College of Material Science and Engineering \\ Henan University of Technology, Zhengzhou, 450001, China \\ liugq1970@126.com
}

Received 24 February 2011; Accepted 26 April 2011

\begin{abstract}
The contraction of poly(methacrylic acid-co-methyl methacrylate) (P(MAA-co-MMA)) gel induced by complexation with linear poly( $N$-vinyl-2pyrrolidone) (PVP) is quite different from that of poly(acrylic acid) (PAA) or poly(methacrylic acid) (PMAA) gel. It was found that the concentration of PVP has a strong effect on the complexation with P(MAA-co-MMA) gel. When PVP was introduced into the P(MAA-co-MMA) network, its dynamic mechanic properties vary greatly between complexed and uncomplexed networks. It had the following results: (1) the higher modulus ratio; (2) a slight contraction of gel.
\end{abstract}

Keywords: Poly( $N$-vinyl-2-pyrrolidone), Poly(methacrylic acid-co-methyl methacrylate), Complex, Dynamic mechanic properties

\section{Introduction}

Polymer gels are hydrophilic, three-dimensional polymeric networks ${ }^{1,2}$ and exhibit drastic volume phase transitions in response to environmental changes, which results in the creation of a novel class of intelligent materials for advanced applications in biotechnology, medicine or industry ${ }^{3-7}$.

Poly( $N$-vinyl-2-pyrrolidone) (PVP) has important applications in various biotechnology areas such as tissueengineering, controlled drug release, separation of biomacromolecules as well as biosensor ${ }^{8,9}$. Poly(methacrylic acid) (PMAA) hydrogels can undergo a volume change in response to $\mathrm{pH}$ stimuli; due to the unique property, PMAA-related polymers have been developed to design $\mathrm{pH}$-sensitive hydrogels that can modulate drug release by change in $\mathrm{pH}^{10-13}$. PVP can form stable complexes with polyacids through hydrogen bonding ${ }^{14,15}$.

In the present study, we design the complexes of poly(methacrylic acid-co-methyl methacrylate) (P(MAA-co-MMA)) network with PVP stabilized by the hydrogen bonding between PMAA and PVP for potential biomaterials. 


\section{Experimental}

Methacrylic acid (MAA), methyl methacrylate (MMA), 2,2'-azobis(isobutyronitrile) (AIBN) and $N, N^{\prime}$-methylenebis(acrylamide) (MBAA) were analytical grade from Chengdu Reagent Factory. Samples of poly( $N$-vinyl-2-pyrrolidone) (PVP) with the $M_{\mathrm{w}}=58000$ (Aldrich) were used as received. MAA and MMA were distilled under reduced pressure before use. AIBN, used as a radical initiator, was recrystallized from ethanol solution. MBAA, used as a crosslinker and PVP were used without further purification.

\section{Preparation}

P(MAA-co-MMA) network was prepared by radical copolymerization of 1.0 mol. $\mathrm{L}^{-1}$ MAA with $1.0 \mathrm{~mol} . \mathrm{L}^{-1} \mathrm{MMA}$ in the presence of $0.01 \mathrm{~mol} . \mathrm{L}^{-1}$ AIBN as initiator and $0.02 \mathrm{~mol} . \mathrm{L}^{-1}$ MBAA as crosslinker in dimethyl sulfoxide. The reaction mixture was bubbled with nitrogen for $15 \mathrm{~min}$ to remove oxygen in the mixture, then injected into the space between two glass plates separated by polyethylene spacers $(3 \mathrm{~mm}$ thick) or into a cylindrical glass tube of diameter $7 \mathrm{~mm}$. Gelation was carried out at $60{ }^{\circ} \mathrm{C}$ for $24 \mathrm{~h}$. After polymerization, the crosslinked P(MAA-co-MMA) was immersed in $4000 \mathrm{~mL}$ ethanol-water mixture (50/50 wt.-\%) for 1 week to remove the monomers and non-crosslinked polymers, then in a large amount water for 3 weeks, until equilibrium was reached. The sample was divided into two parts. One represented as P(MAA-co-MMA) network was still immersed into water. The other part was put in the solution of PVP of various initial concentrations $(3 \mathrm{~mL}$ of the solution per $1 \mathrm{mg}$ of swollen network). The samples were thermostated at $25^{\circ} \mathrm{C}$ for 1 week, then immersed into water for $3 \mathrm{~h}$ to remove PVP absorbed on the surface of P(MAA-co-MMA) / PVP complexes. All specimens were dried under vacuum at room temperature for 7 days.

\section{Composition of complexes}

To obtain information on copolymer composition and polymer yield, a sample of the prepared $\mathrm{P}(\mathrm{MAA}-\mathrm{co}-\mathrm{MMA})$ gels was quenched and then dried under vacuum at room temperature for 10 days to remove solvent and unreacted monomers. The weight loss, except for the solvent, during the drying process was negligible indicating that the monomer-topolymer conversion was nearly $100 \%$ and that the molar ratio of PMAA to PMMA in the copolymer was close to $1: 1$. The composition of the complexes was characterized as follows: by knowing the weight of the dried gel before complexation, the weight of the complexes equilibrated with water (the water on the surface of complex disks was adsorbed before weighing) and the weight of the dried complexes, we could calculate the binding degree ( $\theta$ : molar fraction of PVP/PMMA repeating units in the networks) of PVP with $\mathrm{P}(\mathrm{MAA}-\mathrm{co}-\mathrm{MMA})$ gels. The relative mass of the sample was characterized by $\mathrm{m} / \mathrm{m}_{0}$ ratio, where $\mathrm{m}$ is the mass of the complex at the equilibrium state and $\mathrm{m}_{0}$ is the mass of the gel equilibrated with water.

\section{Measurements}

FTIR spectra were obtained on a Nicolet 200SXV FTIR spectrometer at a resolution of $2 \mathrm{~cm}^{-1}$. A minimum 16 scans were signal averaged. The dried samples were examined as pressed $\mathrm{KBr}$ disks. The thermal analyses were made with a differential scanning calorimeter (Du Pont 9900) over a temperature range from $20{ }^{\circ} \mathrm{C}$ to $180{ }^{\circ} \mathrm{C}$ at a heating rate of $10 \mathrm{~K} / \mathrm{min}$. Thermogravimetric analyses were carried out under a nitrogen flow, with a heating rate of $10 \mathrm{~K} / \mathrm{min}$. Scanning electron microscopy (SEM; model AMRAY 1000) was used to examine the morphologies of the samples. The compression-moulded sample sheets were fractured in liquid nitrogen and the resulting fracture surfaces were then coated with gold and carbon. 


\section{Results and Discussion}

Poly (MAA-co-MMA) networks were prepared and crosslinked by radical copolymerization of MAA with MMA, then was put in the solution of PVP. Scheme 1 shows the synthesis and the expected structure of P(MAA-co-MMA) / PVP complex. Complexes formed between PMAA and PVP are the most stable of the hydrogen-bonded complexes ${ }^{14}$. This stabilization is attributed to the strong intermolecular affinity between the polymer chains and the hydrogen bonding between the carboxyl groups of PMAA and carbonyl groups of PVP is mainly responsible for the interpolymer association. Figure 1 shows the infrared spectra of the carbonyl retching of P(MAA-co-MMA) / PVP complex. The pure PVP gives a broad carbonyl absorption peak at $1682 \mathrm{~cm}^{-1}$. After adding the PVP into P(MAA-co-MMA) networks, the carbonyl stretching frequency is split into two bands at 1682 and $1661 \mathrm{~cm}^{-1}$, corresponding to the free and the hydrogen-bonded carbonyl groups, respectively, which indicates the interactions occurring between PMAA and PVP: a band $v=\mathrm{C}=\mathrm{O}=1661 \mathrm{~cm}^{-1}$ of PVP bound by $\mathrm{H}$-bonds with $-\mathrm{COOH}$ groups of PMAA and a band $\mathrm{v}=\mathrm{C}=\mathrm{O}=1682 \mathrm{~m}^{-1}$ which corresponds to the valence vibrations in the free carbonyl groups of PVP combined into the polycomplex with PMAA. It can be reasonable to conclude that the hydrogen bonds mainly exit in between the PMAA hydroxyl group and the carbonyl group of PVP as shown in Scheme 1.

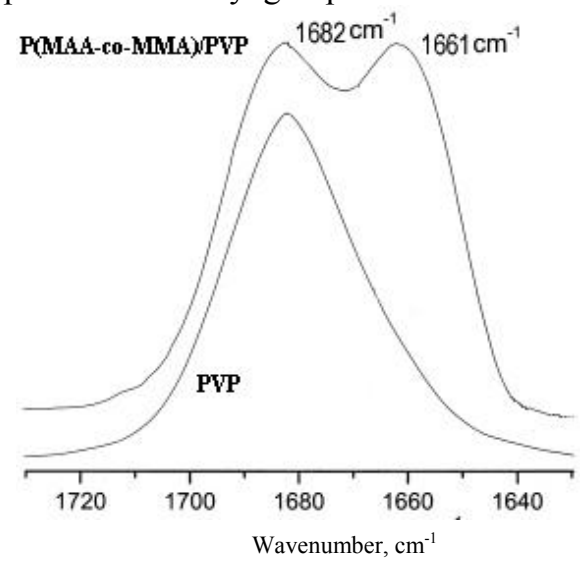

Figure 1. FTIR spectra of PVP and P(MAA-co-MMA)/PVP complexes

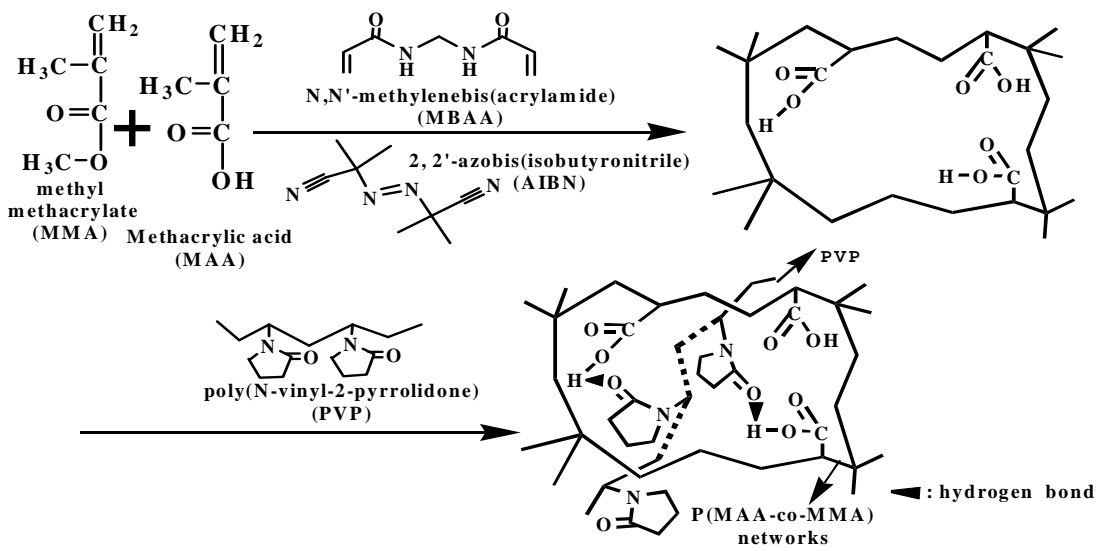

Scheme 1. Synthesis of P(MAA-co-MMA)/PVP complex 
It is reported that the absorption of PEG leads to the sharp shrinkage of the gel volume of PMAA or PAA and the relative mass of the gel is lowered by a factor of $1.5-3.0^{16,17}$; the same phenomenon was reported in the PVP system ${ }^{15}$. Those are called polymer gel collapse. It is to be noted that the transition of weakly cross-linked PMAA or PAA gel from a swollen to the collapsed state is observed at low concentrations of PVP solutions $(<5 \mathrm{wt} \%)$. However, a slight contraction of gel can be observed for P(MAA-co-MMA) gels. Figure 2 (curve 1) illustrates the dependence of the relative mass of the $\mathrm{P}(\mathrm{MAA}-\mathrm{co}-\mathrm{MMA}) / \mathrm{PVP}$ complexes on the initial concentration of $\mathrm{PVP}$ $\left(C_{P}\right)$. The increase of $C_{P}$ up to $35 \mathrm{wt} \%$ leads to a further contraction of the P(MAA-co-MMA) gel. Then, in the large region of PVP concentration (35-40 wt $\%$ ), the relative mass of the gel changes insignificantly. The contraction of the gels takes place as a result of the formation of an intermacromolecular gel-polymer complex on the base of hydrogen bonding. P(MAA-co-MMA) gels are highly hydrophobic compared with PAA gels because the former have MMA component in its backbone chain and MMA units are able to participate in interactions between their hydrophobic group and the main chain of PVP as well as participating in hydrogen bonding, which is the main interacting force. Figure 2 (curve 2) illustrates the dependence of the binding degree $(\theta)$ on initial concentration of PVP. With increasing $C_{P}$ of PVP solution, the $\theta$ value increased simultaneously. This gives the explanation for the conformational changes of P(MAAco-MMA) gel. DSC and DMA results discussed later suggested that no excess PVP is observed and there is only the PVP: PMAA complex phase even in the solution of $C_{P}=40 \mathrm{wt} \%$.

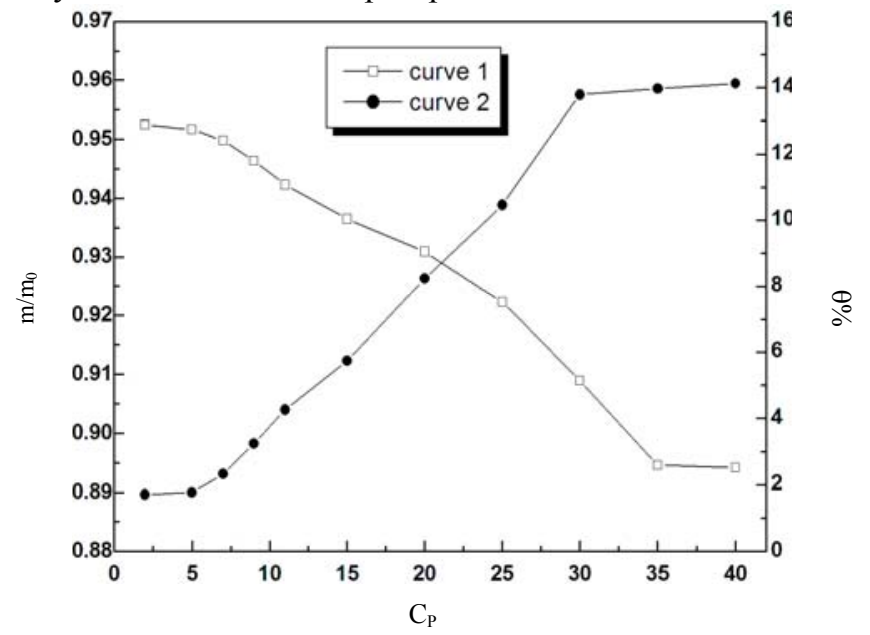

Figure 2. Dependence of the relative mass (curve 1) and binding degree $\theta$ (curve 2) of the P(MAA-co-MMA) / PVP complexes on the initial concentration of PVP

In Figure 2, P(MAA-co-MMA)/PVP complexes have a obviously low $\theta$ value compared with the system P(MAA-co-MMA)/PEG complexes ${ }^{18}$. There are some possible reasons for this effect: (1) a first complexation of a carbonyl group of PVP with an acid group of PMAA may induce the formation of a second hydrogen bond between vicinal - $\mathrm{COOH}$ groups, or each carbonyl can be complexed with the two - $\mathrm{COOH}$ groups simultaneously ${ }^{15}$; (2) the molecular weight of PVP are higher compared with PEG, thus the steric hindrance would hinder the PMAA from forming complex with PVP; (3) the MMA units in the polymer network are uncomplexable and behave as structure defects.

Differential scanning calorimetry (DSC) is extensively used to investigate miscibility in polymer blends or complexes. A single compositionally dependent glass transition is an indication of full miscibility at a dimensional scale between 20 and $40 \mathrm{~nm}^{19}$. Table 1 shows 
the DSC data of P(MAA-co-MMA)/PVP complexes formed in the solution of PVP of various initial concentrations. All P(MAA-co-MMA)/PVP complexes showed only a single glass transition temperature, suggesting that these are fully miscible complexes with a homogeneous amorphous phase. During the heating process, the molecular chain of PMAA/PVP complex phase acts as homogeneously amorphous only during the transfer from the glassy state to the rubbery state.

Table 1. Characteristics of P(MAA-co-MMA) network and P(MAA-co-MMA)/PVP complexes formed in the solution of PVP with various concentrations

\begin{tabular}{ccccc}
\hline Sample & $\mathrm{C}_{\text {pvp }} /\left(\mathrm{wt} .{ }^{\circ} \%\right)$ & $\mathrm{T}_{\mathrm{g}} /{ }^{\circ} \mathrm{C}$ & $\mathrm{E}^{\prime}$ Ratio $^{\mathrm{a}}$ & $\tan \delta$ \\
\hline P(MAA-co- & - & 95 & 4.28 & 0.35 \\
MMA) network & 5 & 82 & 38.8 & 1.03 \\
Complex A & 11 & 80 & 32.5 & 0.92 \\
Complex B & 25 & 78 & 37.0 & 0.86 \\
Complex C & 35 & 77 & 23.4 & 0.96 \\
Complex D & &
\end{tabular}

${ }^{a}$ The Storage Modulus Ratio ( $E^{\prime}$ Ratio) was defined as $\left(E_{T g-20}^{\prime} / E_{T g+20}^{\prime}\right)$

In three-dimensional polymer networks, complexation can significantly affect the network structure. Figure 3 shows the storage modulus of P(MAA-co-MMA)/PVP complexes formed in the solution of various PVP concentrations, and the modulus ratio data are summarized in Table 1. The dynamic mechanical properties vary apparently between complexed and uncomplexed networks. As previously discussed, the change in the dynamic mechanical properties between the P(MAA-co-MMA) network and the P(MAA-coMMA)/PVP complex is primarily due to the cooperative inter-polymer hydrogen bonding which alter the dynamics and structures of the component polymers.

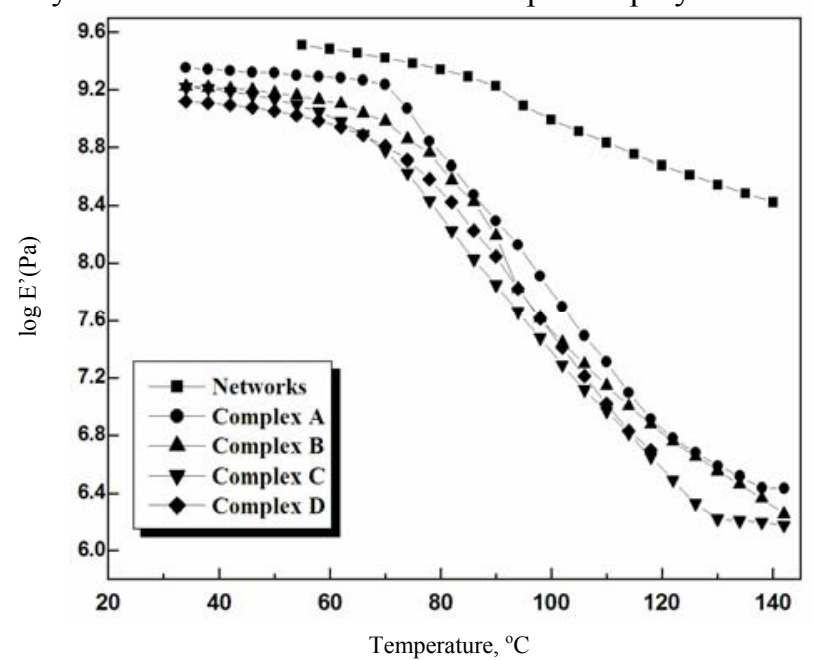

Figure 3. Temperature dependence of tensile storage modulus $\mathrm{E}^{\prime}$ for $\mathrm{P}(\mathrm{MAA}-\mathrm{co}-\mathrm{MMA})$ network and various P(MAA-co-MMA) / PVP complexes

Meanwhile, storage modulus ratio of the complexes increased with the PVP concentration, which is in good agreement with the binding degree $(\theta)$ results shown in Figure 2 (curve 2). This is evidence for the conclusion that the mechanic properties of the 
complexes may be associated with the inter-polymer hydrogen bonding. Loss tangent for the $\mathrm{P}(\mathrm{MAA}-\mathrm{co}-\mathrm{MMA})$ /PVP complex is higher than that of P(MAA-co-MMA) networks, as shown in Table 1 . Since the tan $\delta$ corresponds to the strain energy dissipated by viscous friction, a large tan $\delta$ implies that the material is more likely to be viscous than elastic. This type of complexes may be used for vibration control due to their high loss tangent value since impact energy can be effectively abosorbed.

Finally, it would be interesting to obtain a scanning micrograph of the P(MAA-coMMA) before and after complexation with PVP. Figure 4 (a) shows that the P(MAA-coMMA) looks relatively smooth. In Figure 4 (b), one can see many holes, which are the result of the absorption of PVP. This might be experimental evidence that the contraction is directly associated with the adsorption of PVP onto the surface of P(MAA-co-MMA) networks. The hydrogen bonding between the P(MAA-co-MMA) and the PVP may enhance the interfacial adhesion in P(MAA-co-MMA) / PVP complexes.
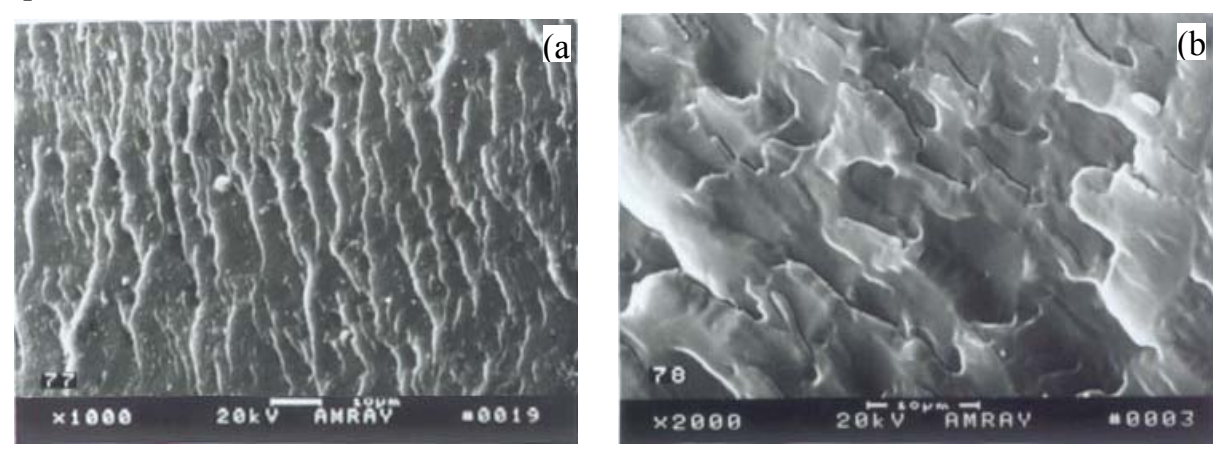

Figure 4. SEM micrographs of the P(MAA-co-MMA) network before and after complexation with PVP: (a) the network without complexation; (b) the P(MAA-coMMA)/PVP complex formed in the solution of PVP with $35 \mathrm{wt} \%$.

\section{Conclusion}

The P(MAA-co-MMA)-PVP complexes was studied by DSC, DMA and SEM. With increasing $C_{P}$ of PVP solution, the binding degree $(\theta)$ value increases simultaneously. However, no excess PVP is observed in the P(MAA-co-MMA) / PVP complexes even if $C_{P}$ reaches $30 \mathrm{wt} .-\%$. Storage modulus ratio increases with the PVP concentrations, which is in good agreement with the $\theta$ results.

\section{References}

1. Gil E S and Hudson S M, Prog Polym Sci., 2004, 29, 1173.

2. Peppas N A, Hilt J Z, Khademhosseini A and Langer R, Adv Mater., 2006, 18, 1345-1360.

3. Soppimath K S, Liu L H, Seow W Y, Liu S Q, Powell R, Chan P and Yang Y Y, Adv Funct Mater., 2007, 17, 355-362.

4. Don T M, Huang M L, Chiu A C, Kuo K H, Chiu W Y and Chiu L H, Mater Chem Phys., 2008, 107, 266.

5. Dimitrov I, Trzebicka B, Müllerc A H E, Dworak A and Tsvetanova C B, Prog Polym Sci., 2007, 32, 1275. 
6. Chen K S , Ku Y A, Lin H R, Yan T R, Sheu D C, Chen T M and Lin F H, Mater Chem Phys., 2005, 91(2/3), 484-489.

7. Lee K Y and Mooney D J, Chem Rev., 2001, 101(7), 1869-79.

8. Ding G, Kamulegeya A, Chen X, Chen J and Liu Y, Int J Pharm., 2007, 328(1,2), 78-85.

9. Wan L S, Xu Z K, Huang X J, Huang X D and Yao K, Acta Biomater., 2007, 3(2), 183-190.

10. Liu Y Y, Fan X D, Kang T and Sun L, Macromol Rapid Commun., 2004, 25, 19121916.

11. Zhang J and Peppas N A, Macromolecules, 2000, 33,102.

12. Mullarney M P, Seery T A P and Weiss R A, Polymer, 2006, 47, 3845-3855.

13. Liu Y Y, Liu W Q, Chen W X, Sun L and Zhang G B, Polymer, 2007, 48, 2665-2671.

14. Lowman A M and Peppas N A, Polymer, 2000, 41, 73-80.

15. Liu S X, Fang Y, Hu D and Gao G, J Appl Polym Sci., 2001, 82, 620-627.

16. Philippova O E, Karybiants N S and Starodubtzev S G, Macromolecules, 1994, 27, 2398.

17. Starodubtzev S G and Philippova O E, Vysokomol Soedin Ser B, 1992, 34, N7, 72.

18. Cao Y, Liu G, Liu X and Ding X, Peng Y and Chan A Chan, New J Chem., 2003, 27, 1065-1069.

19 Kuo S W and Chang F C, Macromolecules, 2001, 34, 4089. 


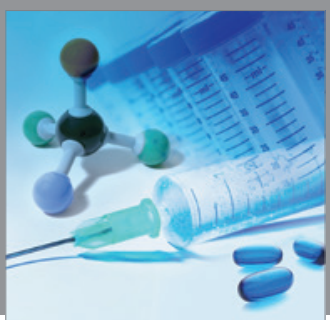

International Journal of

Medicinal Chemistry

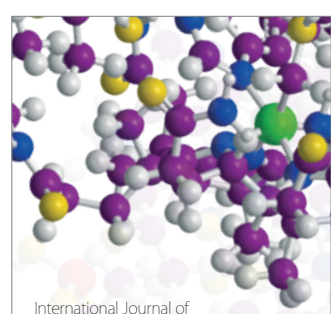

Carbohydrate Chemistry

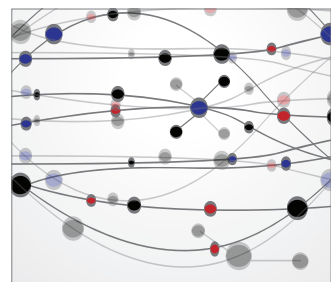

The Scientific World Journal
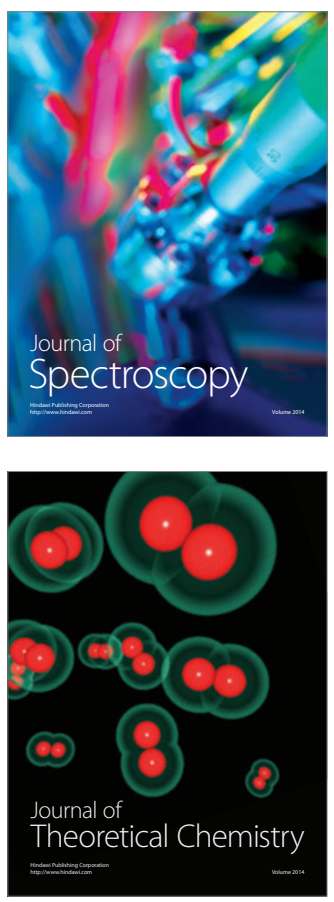
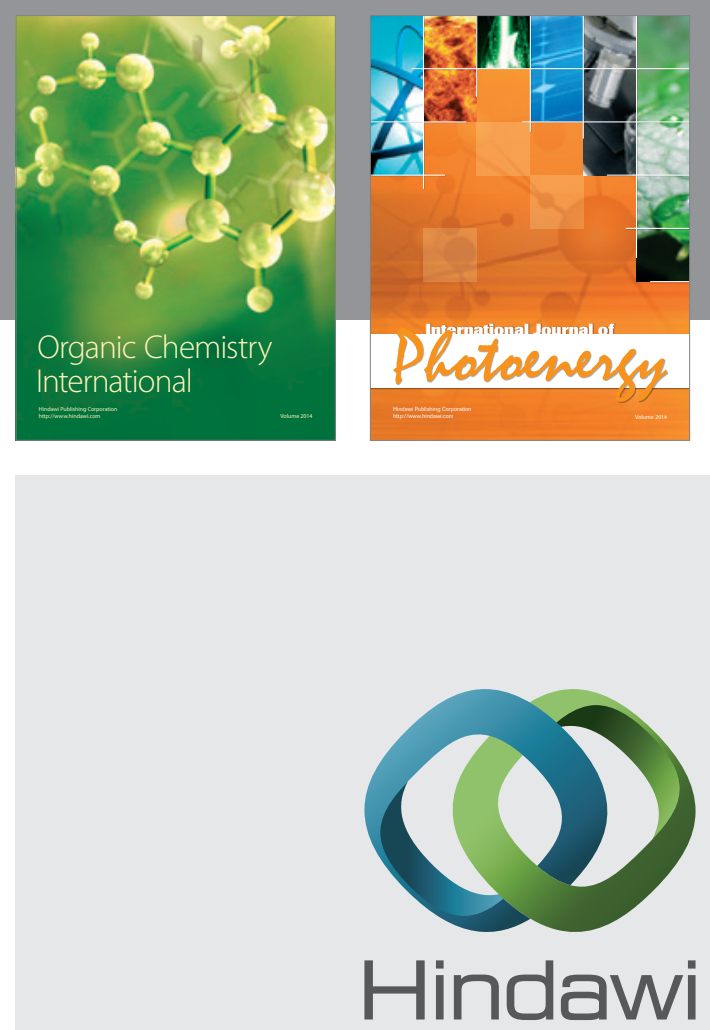

Submit your manuscripts at

http://www.hindawi.com
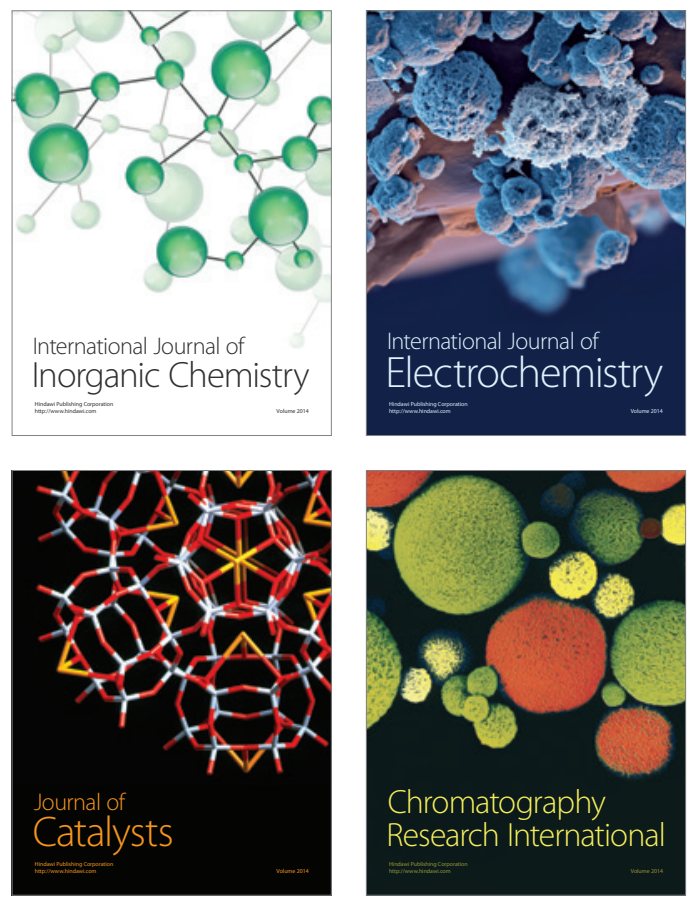
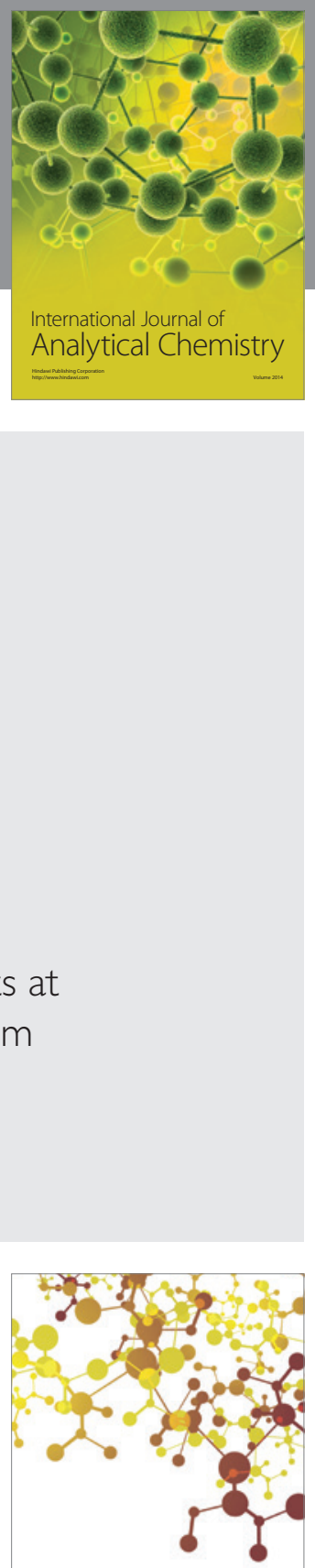

Journal of

Applied Chemistry
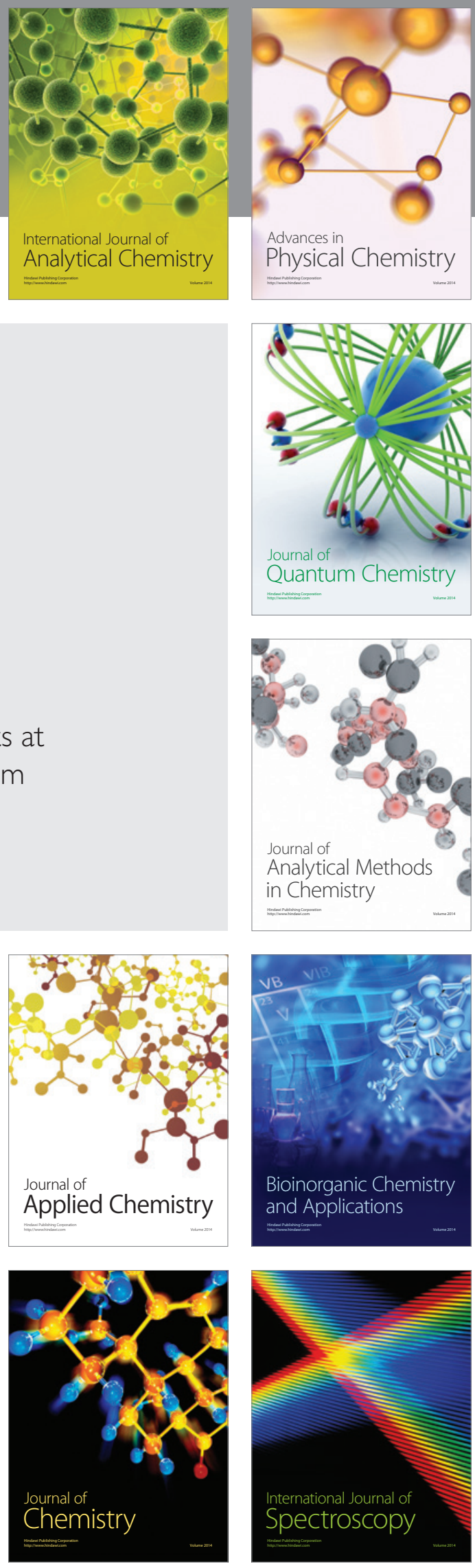